\title{
Students' Perception about Status of Bedside Teaching in Undergraduate Medical Education of Bangladesh
}

\author{
J SULTANA ${ }^{\mathrm{a}}$, I ARA $^{\mathrm{b}}$, MHK TALUKDER $^{\mathrm{c}}$, MMH KHAN $^{\mathrm{d}}$, M SULTANA $^{\mathrm{e}}, \mathrm{S} \mathrm{MUNIRA}^{\mathrm{f}}$
}

\begin{abstract}
Summary:
Introduction: Bedside teaching is the core teaching strategy in the clinical study in undergraduate medical education of Bangladesh. Many of the environments and opportunities available for bedside teaching and learning have changed. Students' views about current status of bed side teaching in Obstetrics and Gynaecology was studied in this study.
\end{abstract}

Methodology: This was a cross sectional study conducted in seven (three public and four private) medical colleges in Bangladesh from July 2012 to June 2013. A total 578, $5^{\text {th }}$ year MBBS students were enrolled who have completed at least 15 days of bedside teaching in Obstetrics and Gynaecology department. A self-administered structured questionnaire (Annex 1) with a five point Likert scale (1strongly disagree, 5-strongly agree) was used for obtaining information from the students. The questionnaire had four main sections- physical environment of bedside sessions, issues regarding patient's comfort and attitude towards patient, teaching tasks, group dynamics and there was a space to write any other comments. Each section had a

Introduction:

Bedside teaching is a vital component of medical education. It is applicable to any situation where

a. Dr. Jobaida Sultana, Associate Professor, Department of Obstetrics and Gynaecology, Shaheed Suhrawardy Medical College \& Hospital, Dhaka, Bangladesh.

b. Prof. Iffat Ara, Professor, Department of Obstetrics and Gynaecology, Dhaka Medical College \& Hospital, Dhaka, Banglades.

c. Prof. Dr. Md. Humayun Kabir Talukder, Professor of Curriculum Development and Evaluation, Center for Medical Education, Mohakhali, Dhaka.

d. Dr. Md. Manir Hossain Khan, Associate Professor, Department of Surgery, BSMMU, Dhaka, Bangladesh.

e. Dr. Mahmuda Sultana, Junior Consultant, Department of Obstetrics and Gynaecology, Deputed in Center for Medical Education, Mohakhali, Dhaka.

f. Dr. Serajoom Munira, Associate Surgeon, Department of Obstetrics and Gynaecology, Shaheed Suhrawardy Medical College \& Hospital, Dhaka, Bangladesh.

Address of Correspondence: Dr. Jobaida sultana, Associate Professor, Department of Obstetrics and Gynaecology,Shaheed Suhrawardy Medical College \& Hospital, Dhaka, Bangladesh. Mobile no: 01819250728, E mail: jobaidasultana @ gmail.com

Received: 12 May 2015

Accepted: 29 May 2017 number of items and total 25 items were observed. For each variable frequency distribution, mean score and standard deviation (SD) were calculated. Here mean score 5- no need of further improvement, as it covered all the required criteria, 4 to $<5$ - very minimum effort, 3 to $<4$ - some effort, 2 to $<3=$ moderate effort, 1to $<2=$ considerable efforts are needed to fulfill the required criteria.

Result: The overall mean score on physical environment factors was 2.75(.44), issues regarding patient's comfort and attitude toward patient was 3.74(.48), teaching tasks was 3.12(.45) and group dynamics was 3.08(.21).

Conclusion: In all aspects of bed side teaching minimum to moderate efforts are necessary to make it more effective. The administrators and teachers should ensure comfortable physical environment in bedside teaching and must learn how to involve patients and learners in the educational process. So along with training on general principles of teaching, the clinical teachers should be provided with special training on bedside teaching skills.

(J Bangladesh Coll Phys Surg 2017; 35: 163-169)

teaching is imparted in the presence of patients ${ }^{1}$. Rather than listening to a presentation or reading from a blackboard, learners have the opportunity to use most of their senses - hearing, vision, smell, and touch - to learn more about the patient and his or her problems ${ }^{2}$.Demonstrating communication skills and physical examination findings, teaching humanistic aspects of clinical medicine, passing 'bad news' and modeling professional behaviors are some essential elements of patient care which cannot be effectively taught in a classroom and require the presence of patient ${ }^{3}$.

Sir William Osler (1849-1920), a renowned clinicianteacher, put emphasis on the importance of bedside teaching. In 1903, he stated "To study the phenomena of disease without books is to sail an uncharted sea, whilst to study books without patients is not to go to sea at all". ${ }^{4}$ In bedside teaching, the educational sessions integrate theory, practical skills, and patient contact to make the educational process as realistic as possible, and they allow the students to develop empathy with the patients ${ }^{2}$. Teaching small groups in the presence of 
the patient allows trainees to be closely observed and taught clinical practice and medical examinations. Besides these educational advantages, there is evidence that patients favor bedside teaching and report better understanding of their illness after participating in bedside teaching 5 .

Despite the fact that bedside teaching is acknowledged for the unique benefits which it brings to the student's learning, the time allocated to bedside teaching has been shown to be on the decline. El-Bagir and Ahmed ${ }^{6}$ reported a decline from ' $75 \%$ of teaching time 30 years ago to just $16 \%$ by 1978 ' and note that it is much lower now. Ramani et al. ${ }^{7}$ reported that estimates of actual time spent at the bedside vary from $15 \%$ to $25 \%$. ElBagir and Ahmed ${ }^{6}$ go on to say that bedside teaching 'has been neglected and rendered haphazard, mediocre and lacking in intellectual excitement, so much so that the clinical examination skills of young doctors have been seriously compromised'. Only $48 \%$ of learners reported that they had been given enough bedside teaching during their undergraduate training, while $100 \%$ thought that bedside learning was the most effective way of learning clinical skills ${ }^{8}$. Several barriers to bedside teaching have been identified ${ }^{9,10}$. Expert educators on bedside teaching have recommended many strategies to make it effective , $^{4,11-13}$.

Various obstacles like time constraints, increased pressure to see more patients, more demand for paperwork, rapid patient discharge, noisy ward, declining bedside teaching skills and over-reliance on technology that prevent doctors from teaching at the bedside have been cited $6,7,9,10$.

Now the importance in providing quality in medical education has been recognized. Many of the environments and opportunities available for bedside teaching and learning have changed dramatically in the last 20 years increased importance of competency based clinical teaching, increased accountability \& increased patient autonomy and changes in knowledge about how students learn ${ }^{1}$. The current practice of bedside teaching was not known in our country. This study was designed to determine the student perspective on status of bedside teaching in different medical colleges in Bangladesh. On the basis of result of which policy makers, educators, researchers can take the different steps and strategies to make bedside teaching more effective.

\section{Methodology:}

This cross sectional study was conducted in 3 public medical colleges (Dhaka Medical College, Sir Salimullah Medical College, Shaheed Suhrawardhi
Medical College) and 4 private medical colleges (Shaheed Mansur Ali Medical College, Uttara Adhunik Medical College, East West Medical College and Medical College for Women, Uttara) in Bangladesh from July 2012 to June 2013. This study was done in Obstetrics and Gynaecology departments. These colleges were included for easy convenience of the researcher.

Convenient sampling method was used for this study. Total $578,5^{\text {th }}$ year MBBS students were enrolled who have completed at least 15 days of bedside teaching in Obstetrics and Gynaecology department. Among 60 days classes, at least 15 days bedside session competed students were included to get more students. To make the homogenisity of the classes only the morning sessions were considered. All the medical colleges had followed the same MBBS curriculum.

A structured self-administered questionnaire (annex-1) with a five point Likert scale (1-strongly disagree, 5strongly agree) was used for obtaining information from the students. The questionaaire had an open question to write any comment. The questionnaire had four main sections- physical environment of bedside sessions, issues regarding patient's comfort and attitude towards patient, teaching tasks, group dynamics and there was a space to write any other comments. Each section had a number of items and total 27 items were observed.

Permission was taken from the respective authority of the medical colleges. Information from the students was collected in lecture classes of selected medical colleges where most of the students were present. After taking permission from the teachers, either first 10 min or last $10 \mathrm{~min}$ of the classes were taken to fill up the questionnaire. Students filled up the questionnaire by themselves after given a brief instruction by the researcher.

Questionnaires were edited after collection and coded manually and were undergone processed and analyzed by using SPSS computer soft ware according to the objectives. Quantitative analysis of information done from structured questionnaire (Table XXVIII-XXXII, Figure I-II) and qualitative analysis done from the open question.

For each variable frequency distribution, mean score and standard deviation (SD) were calculated. Interpretation of mean scores (annex-II) were as follows-

$5=$ No need of further improvement, as it covered all the required criteria.

4 to $<5=$ Very minimum efforts are needed to fulfill the required criteria. 
3 to $<4=$ Some efforts are needed to fulfill the required criteria.

2 to $<3=$ Moderate efforts are needed to fulfill the required criteria.

1 to $<2=$ Considerable efforts are needed to fulfill the required criteria.

There was no ethical problem because all the information was collected after getting permission from the respective authority and confidentiality of the data was maintained.

The main limitation of this study was that the researcher included only the medical colleges present in Dhaka city and not from different other cities of Bangladesh.

\section{Result:}

A total 578 students were surveyed, of whom 338(58\%) were female and $240(42 \%)$ were male (Figure 1). Of the respondents $348(60 \%)$ from public institute and $230(40 \%)$ from private institute (Figure II).

Physical environment of bedside teaching in the ward The mean score on temperature, noise, space and student number were $<3$ and only the mean score on sufficiency of light was $>3$ (Table-1).



Fig.-1: Distribution of the Students by their sex

\section{Issues regarding patient's comfort and attitude toward patient}

Mean scores on these issues were shown in Table-2. The mean score on taking consent, introduction to the patient, maintaining privacy, responding to patients question, sympathy towards patient and giving thanks to the patient were $>3$ and only the mean score on explanation all findings to the patient was $<3$.

\section{Teaching tasks of the teachers}

Table-3 has shown distribution of the students by their opinion on the teaching tasks. The mean scores on patient selection, observation during interviewing patient, observation during physical examination, scope to practice the skills of the session, summarization and timeliness of the teachers were $<3$ and the mean scores on assistance by teacher, asking clinical reasoning skills, giving constructive feedback were $>3$.

\section{Group dynamics of the session}

The mean scores on allocation of individual task and active participation were $<3$ and the mean scores on understanding of group role and finishing task in time were $>3$ (Table 4 )

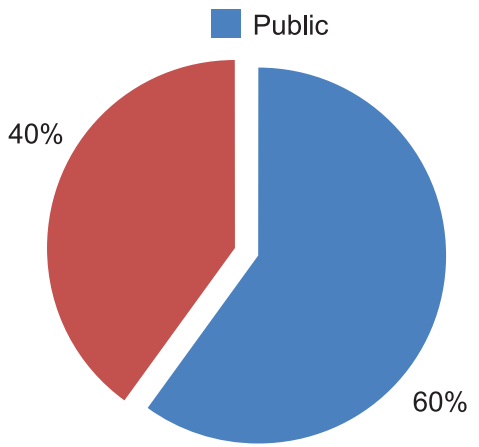

Fig.-2: Distribution of the Students by their institute

Table-I

Distribution of the students by their opinion on physical environment of bedside teaching in the ward

\begin{tabular}{lcc} 
Characteristics & Mean ( SD) & Overall mean score \\
\hline There was comfortable temperature & $2.57(1.14)$ & $2.75(.44)$ \\
There was no disturbance by noise so I had sufficient scope & $2.61(1.15)$ & \\
to clearly listen the patient's words & $3.53(.99)$ \\
There was sufficient light & $2.45(1.17)$ \\
There was adequate space to stand beside the patient so I had & \\
sufficient scope to observe all the activities with the patient & $2.57(1.15)$ \\
$\begin{array}{l}\text { Student number was adequate so everybody had the chance } \\
\text { to participate actively. }\end{array}$ &
\end{tabular}

Rating used a scale of 1-5 ( $1=$ strongly disagree, $5=$ strongly agree $)$ 


\section{Table-II}

Distribution of the respondents by their opinion on the issues regarding patient's comfort and attitude toward patient

\begin{tabular}{lcc} 
Characteristics & Mean(SD) & Overall mean score \\
\hline We had taken informed consent of the patient & $4.04(.94)$ & $3.74(.48)$ \\
I was properly introduced to the patient & $3.98(.82)$ \\
We maintained privacy of the patient & $3.63(1.04)$ \\
All the findings were explained to the patient. & $2.72(.90)$ \\
We responded to the patient's question appropriately & $3.69(.83)$ \\
We were always sympathetized to the patient and paid due attention & $4.08(.79)$ \\
to his discomfort and emotion. & \\
We gave thanks to the patient for his participation. & $4.03(.86)$ \\
\hline
\end{tabular}

Rating used a scale of 1-5 ( $1=$ strongly disagree, $5=$ strongly agree $)$

Table-III

Distribution of the classes on the basis of the teaching tasks of the teachers

\begin{tabular}{lcc} 
Characteristics & Mean ( SD) & Overall mean score \\
\hline Teacher always selected the patient well ahead of the class. & $2.93(1.08)$ & $3.12(.45)$ \\
Teacher observed us during interviewing the patient. & $2.66(1.21)$ \\
Teacher carefully observed us during physical examination. & $2.94(1.12)$ \\
I had adequate scope to practice the skills of the session. & $2.68(1.07)$ \\
Teacher assisted me always during practicing a skill, when needed. & $3.57(.98)$ \\
Teacher encouraged us to think about the diagnosis, differential diagnosis, & $3.97(.79)$ \\
proposing \& interpretting investigations \& outline the treatment. & $3.52(.93)$ \\
Teacher always gave me constructive feedback on my performance. & $2.97(1.06)$ \\
All the time teacher summarized the session effectively. & $2.90(1.17)$ \\
Teacher always started \& finished the classes in time &
\end{tabular}

Rating used a scale of 1-5 ( 1 = strongly disagree, $5=$ strongly agree $)$

Table-IV

Distribution of the students by their opinion on the Group dynamics of the class

\begin{tabular}{lcc} 
Characteristics & Mean ( SD) & Overall mean score \\
\hline I was clear about our group role at the beginning. & $3.01(1.06)$ & $3.08(.21)$ \\
I was clear about my role at the beginning. & $2.93(.99)$ & \\
I was actively participated throughout the classes. & $2.98(1.07)$ & \\
We have finished our every task in time. & $3.39(.96)$ & \\
\hline
\end{tabular}

Rating used a scale of 1-5 ( $1=$ strongly disagree, $5=$ strongly agree $)$

\section{Other comments from the students}

Only 30 students had written their comments. Though the points - timeliness of the teacher, giving chance to practice the skills of the session, small group size, comfortable physical environment which were included in structured questionnaire, students had written their comments on it. Certain additional points came out from their coments were- teacher should be approachable and friendly, classes should be taken as per schedule, teaching should be done in interesting way and more importance given to the female students.

"Teacher should be more dedicated and sincere about bedside teaching. Most of the time we have to find them 
for classes and have to wait for them for a long time. They don't even bother at the end of the ward what we have learnt individually."

"Male students should be given equal chance to practice skills like female students. The thought of only female students will make their career on obstetrics and gynaecology should be changed."

"Please take the class in due time."

"The teachers are sincere but due to large group size effective teaching cannot be possible. "

"Everyone should get equal chance to participate. Some students feel shy and afraid of teachers. They should be encouraged more by the teachers to participate. And the teachers should be more agreeable, considerate, friendly and approachable."

"Students should be encouraged to stand in a single circle so that every student can interact fruitfully."

"Gynae. and Obs. is a huge subject. Teaching should be palatable and interesting, so that we get more interest to this awesome subject."

"As bedside teaching is more effective than lecture, teacher should give more attention to this side"

\section{Discussion:}

Since clinical practice involves the diagnosis and management of the problems in patients, clinical teaching should be carried out on real patients with real problems ${ }^{8}$. The patient's bedside however appear to be one of the most challenging settings for clinical teachers. In curriculum for undergraduate medical education in Bangladesh $(2012)^{14}$, among 5 years course, bedside teaching started from $3^{\text {rd }}$ year. In Obstetrics and Gynaecology, students placed in clinical teaching during $4^{\text {th }}$ year and $5^{\text {th }}$ year. In this subject total teaching hours for lecture, tutorial and integrated teaching is 200 hours and for bedside teaching is 336 hours.

Teaching can be evaluated by external reviewer, internal reviewer, self and by students. Cautions have to be taken during interpretation when teaching is evaluated by students because students have no teaching expertise and they are more prone to biased to friendly behaviors of the teachers.

In this study the mean score for physical environment was $<3$ which is similar to the study done by Amir $\mathrm{N}$ et al.(2016) ${ }^{15}$ where the mean scores were 2.95, 3.32 and 3.42 for $3^{\text {rd }}, 4^{\text {th }}$ and $5^{\text {th }}$ year students respectively. Another study reported that physical clinical environment is not suitable for teaching ${ }^{16}$.In this study only $27 \%$ students agreed that students' number were adequate which is similar to the study done by Islam et al.(2010) ${ }^{17}$ where $63.23 \%$ students reported that large number of students hampered their clinical teaching. According to Nandini C (2015 ) ${ }^{18}, 94.74 \%$ students stated that large group of students around a patient and $73.7 \%$ students quoted that overcrowded unclean wards hamper their clinical teaching. Students usually between two and five are quoted as optimal number for bedside teaching ${ }^{19}$. Evaluation of bedside teaching done by Green-Thompson et al $(2010)^{20}$ reported that in each group there were five students.

Rapport building with patients is very important and without patients cooperation it could be impossible for students to gain the necessary level of training and experience required for their qualification as doctors ${ }^{21}$. There is no doubt that interpersonal communication problems are a major source of patient dissatisfaction and patient non-compliance. The mean scores on the issues regarding patient's comfort and attitude toward patient were relatively high $(>3)$ except explanation to the patient. These high score probably due to the facts that no one is impartial about their self evaluation.

Teacher should select patients who would make for good bedside teaching well ahead of the class ${ }^{1}$. From this study it was found that only $35 \%$ students agreed that teacher always selected the patients well ahead of the class. This study reported that only $31 \%$ students agreed that teacher observed them during interviewing the patient and $40 \%$ students agreed that teacher observed them during physical examination. Study done by Jones P and Rai BP (2015) $)^{22}$ Perceptions of the amount of bedside teaching received were divided. Thirty-five percent either disagreed or strongly disagreed that they had received a good amount of supervised bedside teaching, while $45 \%$ agreed or strongly agreed with this statement. An overwhelming number of cases instructors neglect to observe trainees doing a history or physical exam $^{23}$. The result is that students develop inefficient or frankly wrong practice habits based on their perceptions of how interviewing and examination should be carried out.

Only $27 \%$ students agreed that they had adequate scope to practice the skills of the session. In order to achieve active learning, all students must be allowed to actively take part in interaction with the patients and make independent decisions regarding patient diagnosis and management. The optimal approach to achieve this would involve students seeing patients on a one to one basis $^{24}$. 
Mean score on teacher assisted me always during practicing a skill, teacher encouraged us to think about the diagnosis, differential diagnosis, proposing \&interpreting investigations \& outline the treatment were high. In one study it was observed that teachers most of the time did the passive actions- asking closed questions, demonstrating a procedure, sharing knowledge in didactic manner other than asking open ended questions or to apply clinical reasoning skills ${ }^{13}$.

$56 \%$ students agreed that teacher always gave them constructive feedback on their performance which differ from other studies where it was found that clinical teachers either omit to give feedback altogether or the quality of their feedback does not enlighten the learners of their strengths and weakness ${ }^{16}$. One of the reasons behind this inappropriate feedback is failure to observe the trainee's performance during history taking \& physical examination. This difference in findings is due to the fact that students did not know what are the things should be included in feedback.

Only $37 \%$ students agreed that all the time teacher summarized the session effectively. This teaching skill can be acquired if the teachers are provided with adequate training in medical education. $36 \%$ students agreed that teacher always started \& finished the classes in time.

A focus group study ${ }^{25}$ was done with undergraduate medical students and found that there were frequent cancellation or rescheduling of the clinical classes and students believed that the consultant was too busy in doing other things.

From this study it was found that $38 \%, 32 \%, 37 \%$ and $52 \%$ students agreed that they were clear about their group role, clear about their individual role at the beginning, actively participated and finished their every task in time respectively. An observational study ${ }^{13}$ revealed a dominance of passive and low level cognitive actions across learning sessions, particularly bedside teaching. It was reported in different studies that one of the common problems of BST session is lack of clear objectives and expectations ${ }^{16}$.

Comment from the open questionnaire, the timeliness of teacher was often questioned, which is also similar to the study done by Al-Swailmi FK et al. $(2016)^{26}$. Students expression reported by Jayasuriya-Illesinghe $\mathrm{V}(2016)^{27}$ about role modeling, and purposive teaching at bed side.
Students comment for role modeling teaching-

"Sometimes we walk with the consultant during ward rounds for 3-4 hours and they say about 4 words to us, they could tell us to vanish off, they don't, they just let us stay and don't teach a word"(respondent 2).

For purposive teaching-

By the end of the ward class we were happy about what we have leant, not just relieved that it [teaching session] was over, there was something left after the class" (respondent 12).

Clinical teachers have a dual role in medicine, to provide patient care and to teach ${ }^{28}$. Though all doctors are well prepared for their clinical roles, few are trained for their teaching roles ${ }^{29}$. Most lack knowledge of educational principles and teaching strategies thus may be inadequately prepared for this additional professional role ${ }^{30}$. So, all clinical teachers should be provided with the training on bedside teaching. Along with this, provision of adequate facilities on the ward for bedside teaching, introduction of reward systems of teachers for good teaching, protected time for teaching, incorporation of ward staffs, written information of patient about bedside teaching and dividing the students in small group enhances the bed side teaching experience for patients, students and teachers.

\section{Conclusion:}

High quality medical education is a fundamental aspect of high quality medical care. In all aspects of bedside teaching minimum to moderate efforts are necessary to make it effective. Bedside teaching is a demanding, complex and often difficult task, a task many clinicians assume without adequate preparation or orientation. A bedside teacher must learn how to involve patients and learners in the educational process. Maintaining a comfortable environment for all participants; the learner, the patient and the bedside teacher is very important. Along with training on general principles of teaching, the clinical teachers should be provided with special training on bedside teaching skills. Further observational studies and views of bedside teachers are needed in different subjects of medical science.

\section{References}

1. Gill, D. Teaching and Learning 'At the Bedside'. Avilable from www. faculty. londondeanery. ac. uk/ teaching and learning at the bedside; 2007.

2. Ray S \& Ganguli P. Bedside teaching. Avilable from Careers.brij.com/ careers/ advice/view-article. html2. $\mathrm{d}=20000377 ; 2009$. 
3. Fitzgerald FT. Bedside teaching. West J Med 1993;158: 418-20.

4. Ramani S. Twelve tips to improve bedside teaching, Med Teacher 2003;25:112-5.

5. Lehmann LS, Brancati FL, Chen M, Roter D \& Dobs AS. The effect of bedside case presentations on patients' perceptions of their medical care. New England Journal of Medicine 1997;336: 1150-1155.

6. Ahmed M El-Bagir K. What is happening to bedside teaching? Med Educ 2002; 36: 1185-8.

7. Ramani S, Orlander JD, Strunin L, Barber TW. Whither bedside teaching? A focus group study of clinical teachers. Acad Med 2003 Apr; 78(4):384-90.

8. Nair B, Coughlan JL \& Hensley MJ. Student and patient perspectives on bedside teaching. Medical Education 1997; 31: $341-346$.

9. La Combe MA. On bedside teaching. Ann Int Med 1997 ; 126: $217-20$.

10. Nair B, Coughlan JL \& Hensley MJ. Impediments to bedside teaching. Med Educ 1998; 32: 159-62.

11. Janicik RW \& Fletcher KE. Teaching at the bedside: a new model, Medical Teacher 2003; 25(2): 127-130.

12. Reilly BM. Inconvenient truths about effective clinical teaching. Lancet 2007; 370: 705-711.

13. Young L, Orlandi A, Galichet B \& Heussler H. Effective teaching and learning on the wards: easier said than done? Medical Education 2009; 43: 808-817.

14. Curriculum for Undergraduate Medical Education in Bangladesh-Updated 2012. Bangladesh Medical \& Dental Council (BM\&DC), Dhaka-1000. Sept 2012, pp-392-393.

15. Amir N, Roslan L, Tang B, Samarahan K, Syafawani N, Sarawak B et al. The Perception Of Medical Students In Clinical Years Towards Bedside Teaching In Universiti Malaysia Sarawak(Unimas) Journal of Borneo Kalimantan2016, 2 (2). ISSN 2289-2583

16. Ramani S \& Leinster S. AMEE Guide NO. 34: Teaching in the clinical environment. Medical Teacher 2008; 30 : 347-364.

17. Islam MS, Khan I, Talukder MHK \& Akhter N. Clinical teaching in Dermatology of undergraduate Medical students of Bangladesh. Bangladesh Journal of Medical Education 2010; 1(1): 16-20.
18. Nandini C, Suvajit D, Kaushik M, and Chandan C. Students' and Teachers' Perceptions of Factors Leading to Poor Clinical Skill Development in Medical Education: A Descriptive Study. Education Research International Volume 2015 (2015), Article ID 124602, 3 page http://dx.doi.org/10.1155/2015/124602

19. Dent JA \& Harde, RM. A Practical Guide for Medical Teachers, London: Churchill Livingstone, 2001, pp. 97-105.

20. Green-Thompson L, Mcinerney P, Veller M. The evaluation of bedside teaching- an instrument for staff evaluation and student experiences: A pilot study at a South African university.SAJS 2010; 48( 2): 50-52.

21. Chipp E, Stonely S \& Cooper K. Clinical placement for medical students: factors affecting patient involvement in medical education. Medical Teacher 2004; 26(2): 114-119.

22. Jones P and Rai BP. The status of bedside teaching in the United Kingdom: the student perspective. Adv Med Educ Pract 2015; 6: pages 421—429

23. Mcleod PJ \& Harden RM. Clinial Teaching strategies for physicians. Medical Teacher 1985; 7(2): 173-189.

24. Sanson-Fisher RW, Rolef IE \& Williams N. Competency based teaching: the need for a new approach to teaching clinical skills in the undergraduate medical course. Medical Teacher 2005; 27(1): 29-36.

25. Stark P. Teaching and learning in the clinical setting: a qualitative study of the perceptions of students and teachers. Medical Education 2003; 37: 975-982.

26. Al-Swailmi FK, Khan IA, Mehmood Y, Al-Enazi SA, Alrowaili M and Al-Enazi MM. Students' perspective of bedside teaching: A qualitative study Pak J Med Sci. 2016 Mar-Apr; 32(2): 351-355.

27. Jayasuriya-Illesinghe VJ, Nazeer I, AthaudaL and Perera J. Role Models and Teachers: medical students perception of teaching-learning methods in clinical settings, a qualitative study from Sri Lanka. https:/www.researchgate.net/ publication/2016/293636303

28. Prideaux D, Alexander H, Bower A, Dacre J, Haist S, Jolly $\mathrm{B}$, et al. Clinical teaching: maintaining an educational role for doctors in the new health care environment. Med Educ 2000; 34: 820-826.

29. Steinert Y. Staff development for clinical teachers. Clin Teach 2005; 2: 104-110.

30. Wilkerson L, Irby DM. Strategies for improving teaching practices: a comprehensive approach to faculty development. Acad Med 1998; 73: 387-396. 